\title{
INFLUÊNCIA DAS RESTRIÇÕES NA LEALDADE DOS ESPECTADORES DE FUTEBOL: SPORT LISBOA E BENFICA
}

\author{
MS. JORGE MIGUEL RODRIGUES DE PINA CARDOSO \\ Mestrado em Gestão do Desporto, Faculdade de Motricidade Humana, \\ Universidade de Lisboa (Lisboa - Lisboa - Portugal) \\ E-mail: jmrdepc@gmail.com
}

\author{
DR. ABEL HERMÍNIO LOURENÇO CORREIA \\ Departamento de Educação, Ciências Sociais e Humanidades, \\ Faculdade de Motricidade Humana, Universidade de Lisboa \\ (Lisboa - Lisboa - Portugal) \\ E-mail: acorreia@fmh.utl.pt
}

\section{DR. RUI DANIEL GASPAR NETO BISCAIA}

Departamento de Educação, Ciências Sociais e Humanidades, Faculdade de Motricidade Humana, Universidade de Lisboa

(Lisboa - Lisboa - Portugal)

E-mail: rbiscaia@fmh.utl.pt

\begin{abstract}
RESUMO
O objetivo do estudo foi analisar a influência das restrições na lealdade dos espectadores de futebol. Foi aplicado um questionário a adeptos do Sport Lisboa e Benfica e através de uma análise fatorial exploratória identificaram-se II fatores. Uma análise de regressão linear permitiu identificar que 4 influenciam significativamente a lealdade dos adeptos. Os resultados dos testes ANOVA identificaram a existência de diferenças estatisticamente significativas entre restrições sentidas por sócios e não sócios, bem como entre espectadores com diferentes habilitações escolares. Quanto à lealdade, verificaram-se diferenças entre sócios e não sócios. As implicações dos resultados são discutidas e fornecem-se sugestões para futuras pesquisas.

PALAVRAS-CHAVE: Restrições; lealdade; futebol; espectadores.
\end{abstract}


Segundo Casper, Kanters e James (2009) a capacidade de compreender e prever o comportamento dos espectadores desportivos é fundamental para os clubes. Esta observação nunca foi tão atual no mundo do desporto como nos dias que correm. Uma indústria que todos os anos movimenta milhares de milhões de euros, seja em receitas de bilheteria, direitos televisivos ou merchandising, tem de conhecer os desejos e os anseios do seu público-alvo e, simultaneamente, compreender as restrições que o podem afastar no sentido de minorar os seus efeitos nefastos.

Entre todas as modalidades que a indústria desportiva engloba, não há nenhuma mais reconhecida a nível planetário do que o futebol profissional (RICHELIEU; LOPEZ; DESBORDES, 2008). Seja relativamente aos níveis das receitas que gera, com valores na ordem dos 15,7 milhões de euros só no mercado europeu, seja em número de adeptos e espectadores da modalidade (DELOITTE, 20 I 0).

Quanto à realidade do futebol em Portugal e do fenômeno de atração que gera, há a salientar que se trata do desporto favorito dos espectadores desportivos portugueses (MARIVOET, 200I). De acordo com a Liga Portuguesa de Futebol Profissional (LPFP), esta modalidade contou com uma assistência de 2.419.683 espectadores na época 20 I0/20 I I (LPFP, 20 I I), o que deu uma média de I0.082 por jogo. Por sua vez, o clube com mais espectadores em Portugal foi o Sport Lisboa e Benfica (SLB), com uma assistência total de 572. 197 espectadores nos I 5 jogos realizados em casa na referida época desportiva.

Analisando-se os números referidos, percebe-se a relevância que tem para a gestão desportiva, a compreensão das restrições que influenciam os adeptos de futebol a assistir a um jogo de futebol no estádio, na medida em que a diminuição do número de espectadores vai levar a uma diminuição das receitas geradas pela bilheteria. É neste enquadramento que surgem os estudos sobre as restrições no lazer, estudos esses que pretendem investigar os fatores compreendidos pelos indivíduos como inibidores ou limitadores de uma experiência de lazer completamente satisfatória (JACKSON; CRAWFORD; GODBEY, I 993; ALEXANDRIS; CARROL, 1997; PETRICK et al., 200 I ; JACKSON, 2000). Para além da identificação dos fatores condicionantes da ida ao espetáculo desportivo, é fundamental também verificar o impacto das restrições nos comportamentos futuros dos espectadores para se compreender a lealdade ao clube. $\bigcirc$ contexto de lealdade no desporto é único devido aos processos psicológicos inerentes ao consumo desportivo, aos atributos e benefícios percebidos pelos consumidores e ao envolvimento e à identificação com as equipes desportivas (BEE; HAVITZ, 20I0; TAPP, 2004; NEALE; FUNK, 2006). Estes comportamentos de lealdade podem-se descrever como o ato de 
assistir a mais jogos no estádio, recomendar a assistência a amigos ou familiares ou adquirir merchandising do clube (MAHONEY; MADRIGAL; HOWARD, 2000). De acordo com Bee e Havitz (20 l0), espectadores leais são a chave para o sucesso de qualquer organização. É a lealdade dos fãs que os mantém indefectíveis no apoio quando a sua equipe fraqueja no campo, que transfere as suas preferências pessoais para os patrocinadores da sua equipe e que os torna mais suscetíveis de adquirirem merchandising do clube (NEALE; FUNK, 2006; MAHONEY; MADRIGAL; HOWARD, 2000).

De acordo com a importância do estudo das restrições na compreensão da lealdade do espectador e da ausência de estudos no âmbito do futebol, o presente estudo tem como objetivo principal a identificação das restrições que influenciam os comportamentos de lealdade dos espectadores de futebol. Adicionalmente pretende-se analisar o efeito das restrições na lealdade dos espectadores e perceber se existem diferenças entre os espectadores mediante as suas caraterísticas sociodemográficas.

\section{MATERIAIS E MÉTODOS}

\section{AMOSTRA E PROCEDIMENTOS}

A amostra deste estudo foi composta por sócios e adeptos do SLB que aceitaram participar de forma voluntária e com garantia de anonimato das suas respostas. Com autorização do clube foi ativado um link na webpage oficial do SLB e solicitou-se aos sócios e adeptos o preenchimento de um questionário. O questionário esteve ativo durante o mês de Maio de 20 I I e obtiveram-se 388 respostas. Posteriormente foram eliminados os questionários preenchidos por menores de 16 anos e os que apresentavam mais de 9 respostas seguidas com a mesma valoração. A amostra final foi composta por 305 participantes.

\section{INSTRUMENTO}

O questionário utilizado tinha três partes e foi elaborado segundo a literatura, de acordo com a especificidade do espetáculo de futebol. A primeira parte, dedicada às restrições internas, foi composta por 13 itens, sendo 10 itens derivados de Kim e Trail (20 I 0) e 3 itens derivados de Dale et al. (2005). A segunda parte, num total de 34 itens, foi dedicada às restrições externas. Para o efeito, utilizaram-se 21 itens dos propostos por Kim e Trail (20 I 0) e 13 itens da autoria de Dale et al. (2005) e Ingen e Eijck (2009). Para avaliar a lealdade foram utilizadas duas subescalas. Uma subescala para medir a intenção de assistir a mais jogos, composta pelos 3 itens propostos por Yoshida e James (2010) e uma segunda subescala também com 3 
itens para medir a intenção de comprar merchandising, tal como proposto por Kim e Trail (20 I0). A tradução dos itens para a língua portuguesa foi efetuada por um licenciado em gestão do desporto com vasta experiência no futebol e revista por três investigadores seniores da área da gestão do desporto e um tradutor profissional.

Todos os itens foram avaliados através de uma escala de Likert com 7 pontos, com os pontos extremos de I (Discordo Totalmente) e 7 (Concordo Totalmente), sendo que nas dimensões das restrições era concedida a opção de resposta Não Aplicável, devido ao teor potencialmente não aplicativo de alguns itens (por exemplo, os transportes públicos).

\section{ANÁLISE DE DADOS}

Os dados foram analisados no Statistical Package for the Social Sciences (SPSS 19.0). Foi efetuada uma análise descritiva para se caraterizar a amostra. Para identificar as restrições dos espectadores, foi efetuada uma análise fatorial exploratória (AFE) com método dos componentes principais e rotação varimax. Utilizou-se o $\mathrm{KMO}$ e o teste de esfericidade de Bartlet para se analisar as correlações simples com as correlações parciais observadas entre as variáveis. Para retenção dos fatores consideram-se os valores de eigenvalue superiores a I (MAROCO, 20 I0). A consistência interna foi avaliada através do alfa de Cronbach. A identificação dos preditores da lealdade foi feita através de uma análise de regressão linear. Os testes One Way ANOVA foram utilizados para se comparar as restrições e a lealdade dos espectadores, de acordo com o gênero, as habilitações escolares, a filiação no clube e a prática de futebol federado.

\section{RESULTADOS}

\section{CARACTERIZAÇÃO SOCIODEMOGRÁFICA E DETERMINAÇÃO DAS RESTRIÇÕES}

A análise sociodemográfica permitiu identificar que a maioria dos inquiridos é do gênero masculino (81\%) e a maioria tem entre 20 e 30 anos (50,5\%). Praticamente metade indicou assistir a 4 ou menos jogos por época $(50,2 \%)$ e a maioria não praticou futebol federado (92,8\%). Aproximadamente dois terços são sócios do SLB (61,3\%) e mais de metade frequentou o ensino superior (57\%).

Nas Tabelas I e 2 são apresentados os fatores identificados pelos espectadores como restrições na ida ao espetáculo futebol. 
Tabela I. Resultados da análise fatorial exploratória (varimax rotation). Fator I a 5

\begin{tabular}{|c|c|c|c|c|c|}
\hline Fatores/ltens* & Loading & Eingenvalue & \% Variância & \% Acumulada & $\alpha$ \\
\hline FI - Acessibilidades & & 11,02 & 23,44 & 23,44 & 0,88 \\
\hline $\begin{array}{l}\text { A má localização dos estacionamentos } \\
\text { e acesso ao Estádio da Luz }\end{array}$ & 0,850 & & & & \\
\hline A falta de transportes públicos & 0,576 & & & & \\
\hline A fraca acessibilidade ao Estádio da Luz & 0,816 & & & & \\
\hline $\begin{array}{l}\text { A distância do estacionamento } \\
\text { ao Estádio da Luz }\end{array}$ & 0,841 & & & & \\
\hline $\begin{array}{l}\text { A falta de espaço no Estádio da } \\
\text { Luz para lidar com multidões }\end{array}$ & 0,523 & & & & \\
\hline $\begin{array}{l}\text { A dificuldade em estacionar no Estádio } \\
\text { da Luz }\end{array}$ & 0,845 & & & & \\
\hline A insegurança nos transportes públicos & 0,554 & & & & \\
\hline F2 - Alternativas de Lazer & & 4,37 & 9,30 & 32,74 & 0,86 \\
\hline Ver outros desportos na televisão & 0,520 & & & & \\
\hline Estar no computador & 0,741 & & & & \\
\hline Ver televisão & 0,723 & & & & \\
\hline $\begin{array}{l}\text { Ver jogos de futebol de outras } \\
\text { equipes na televisão }\end{array}$ & 0,683 & & & & \\
\hline Ir a um bar & 0,707 & & & & \\
\hline Ir ao ginásio & 0,760 & & & & \\
\hline Ver os jogos do Benfica na televisão & 0,540 & & & & \\
\hline Ver os jogos do Benfica na Internet & 0,541 & & & & \\
\hline F3 - Falta de Interesse e Companhia & & 3,67 & 7,80 & 40,54 & 0,91 \\
\hline $\begin{array}{l}\text { Não ter companhia para ir } \\
\text { aos jogos do Benfica }\end{array}$ & 0,700 & & & & \\
\hline $\begin{array}{l}\text { Não ter familiares interessados } \\
\text { em ir aos jogos do Benfica }\end{array}$ & 0,643 & & & & \\
\hline $\begin{array}{l}\text { Não ter amigos interessados } \\
\text { em ir aos jogos do Benfica }\end{array}$ & 0,845 & & & & \\
\hline $\begin{array}{l}\text { Não ter o(a) companheiro(a) } \\
\text { disponível para ir ao futebol }\end{array}$ & 0,839 & & & & \\
\hline $\begin{array}{l}\text { Não ter amigos disponíveis } \\
\text { para ir ao futebol }\end{array}$ & 0,857 & & & & \\
\hline $\begin{array}{l}\text { Não ter o(a) companheiro(a) } \\
\text { interessado(a) em ir aos jogos } \\
\text { do Benfica }\end{array}$ & 0,880 & & & & \\
\hline F4 - Falta de Sucesso & & 2,61 & 5,55 & 46,09 & 0,91 \\
\hline $\begin{array}{l}\text { O Benfica ter resultados } \\
\text { não satisfatórios }\end{array}$ & 0,875 & & & & \\
\hline O Benfica não ganhar muitos jogos & 0,802 & & & & \\
\hline O Benfica não estar a lutar pelo título & 0,839 & & & & \\
\hline
\end{tabular}




\begin{tabular}{lccccc}
\hline Fatores/ltens* & Loading & Eingenvalue & \% Variância & \% Acumulada & $\alpha$ \\
\hline $\begin{array}{l}\text { O Benfica não estar a jogar } \\
\text { como gostaria }\end{array}$ & 0,861 & & & & \\
F5 - Custos & & 2,52 & 5,35 & 51,44 & 0,90 \\
O elevado custo financeiro para ir aos & 0,864 & & & & \\
jogos do Benfica & & & & \\
O elevado preço do bilhete para ir a & 0,895 & & & \\
um jogo do Benfica & & & & \\
O elevado preço dos bilhetes de época & 0,801
\end{tabular}

Tabela 2. Resultados da análise fatorial exploratória (varimax rotation). Fator 6 a I I

\begin{tabular}{|c|c|c|c|c|c|}
\hline Fatores/ltens* & Loading & Eingenvalue & \% Variância & $\%$ Acumulada & $\alpha$ \\
\hline F6 - Falta de Conhecimento & & 2,00 & 4,27 & 55,71 & 0,88 \\
\hline $\begin{array}{l}\text { Não compreender os aspectos } \\
\text { técnicos do futebol }\end{array}$ & 0,907 & & & & \\
\hline $\begin{array}{l}\text { Não compreender as regras do } \\
\text { futebol }\end{array}$ & 0,922 & & & & \\
\hline $\begin{array}{l}\text { Não compreender a tática no } \\
\text { futebol }\end{array}$ & 0,897 & & & & \\
\hline F7 - Segurança & & ।,91 & 4,06 & 59,76 & 0,86 \\
\hline $\begin{array}{l}\text { A falta de segurança nas entradas } \\
\text { e saídas no Estádio da Luz }\end{array}$ & 0,800 & & & & \\
\hline $\begin{array}{l}\text { A insegurança nas acessibilidades } \\
\text { ao Estádio da Luz }\end{array}$ & 0,816 & & & & \\
\hline $\begin{array}{l}\text { A falta de segurança nas bancadas } \\
\text { durante os jogos }\end{array}$ & 0,822 & & & & \\
\hline $\begin{array}{l}\text { F8 - Alternativas de Prática } \\
\text { Desportiva }\end{array}$ & & 1,63 & 3,47 & 63,23 & 0,75 \\
\hline Praticar atividade física & 0,761 & & & & \\
\hline $\begin{array}{l}\text { Participar em atividades de } \\
\text { desporto recreação }\end{array}$ & 0,831 & & & & \\
\hline F9 - Compromissos & & 1,29 & 2,74 & 65,97 & 0,65 \\
\hline Ter compromissos escolares & 0,740 & & & & \\
\hline Ter compromissos com amigos & 0,487 & & & & \\
\hline Ter compromissos familiares & 0,738 & & & & \\
\hline FIO - Localização & & 1,19 & 2,52 & 68,50 & 0,60 \\
\hline $\begin{array}{l}\text { A distância a percorrer para chegar } \\
\text { ao Estádio da Luz }\end{array}$ & 0,818 & & & & \\
\hline A localização do Estádio da Luz & 0,664 & & & & \\
\hline FII - Programação Desportiva & & 1,12 & 2,39 & 70,89 & 0,60 \\
\hline Horário do jogo & 0,537 & & & & \\
\hline Dia do jogo & 0,792 & & & & \\
\hline
\end{tabular}


Os resultados da AFE permitiram identificar I I fatores que explicaram mais de dois terços da variância dos dados (70,89\%). O valor do KMO $(0,804)$ e do teste de Bartlett $(\lambda<0.00$ I $)$ indicaram existir uma boa correlação entre as variáveis do modelo, sendo os scores obtidos posteriormente utilizados nas análises inferenciais.

\section{INFLUÊNCIA DAS RESTRIÇÕES NAS INTENÇÕES DE COMPORTAMENTO LEAL DOS ESPECTADORES DE FUTEBOL}

A subescala de intenção de assistir a mais jogos apresentou boa consistência interna $(\alpha=0,78)$. Quanto à análise de regressão efetuada, verificou-se que as restrições permitem explicar apenas $13.4 \%$ da intenção de assistir a mais jogos (TABELA 3). Foram identificados três fatores que explicam a influência negativa das restrições na intenção de assistir a mais jogos, sendo eles as alternativas de lazer $(\beta=-0,267)$, as acessibilidades $(B=-0,194)$ e as alternativas de prática desportiva $(B=-0,179)$.

Tabela 3. Análise da regressão dos fatores para explicar as intenções de comportamento

\begin{tabular}{|c|c|c|c|c|c|}
\hline \multirow[b]{2}{*}{ Fatores } & \multicolumn{2}{|c|}{$\begin{array}{l}\text { Unstandardized } \\
\text { Coefficients }\end{array}$} & \multirow{2}{*}{$\begin{array}{c}\begin{array}{c}\text { Standardized } \\
\text { Coefficients }\end{array} \\
\text { Beta }(B)\end{array}$} & \multirow[b]{2}{*}{$\mathrm{t}$} & \multirow[b]{2}{*}{ Sig. } \\
\hline & B & Std. Error & & & \\
\hline (Constante) & 5,449 & 0,099 & & $54,8 \mid 5$ & 0,000 \\
\hline Acessibilidades & $-0,264$ & 0,100 & $-0,194$ & $-2,644$ & 0,009 \\
\hline Alternativas de Lazer & $-0,363$ & 0,100 & $-0,267$ & $-3,638$ & 0,000 \\
\hline Falta de Interesse e Companhia & 0,014 & 0,100 & 0,010 & $0,|4|$ & 0,888 \\
\hline Falta de Sucesso & $-0,132$ & 0,100 & $-0,097$ & $-1,320$ & 0,189 \\
\hline Custos & $-0,156$ & 0,100 & $-0,115$ & $-1,562$ & 0,120 \\
\hline Falta de Conhecimento & 0,180 & 0,100 & 0,132 & 1,806 & 0,073 \\
\hline Segurança & $-0,050$ & 0,100 & $-0,037$ & $-0,500$ & 0,618 \\
\hline Alternativas de Prática Desportiva & $-0,244$ & 0,100 & $-0,179$ & $-2,443$ & 0,016 \\
\hline Compromissos & $-0,102$ & 0,100 & $-0,075$ & $-1,026$ & 0,306 \\
\hline Localização & 0,096 & 0,100 & 0,070 & 0,961 & 0,338 \\
\hline Programação Desportiva & 0,025 & 0,100 & 0,019 & 0,252 & 0,801 \\
\hline
\end{tabular}

$F(3,268)=57,537, p<0,01 ; R 2=0,193 ; R 2$ ajustado $=0,134$

\section{INFLUÊNCIA DAS RESTRIÇÕES NAS INTENÇÕES DE COMPRA DE MERCHANDISING PELOS ESPECTADORES DE FUTEBOL}

A subescala de intenção de compra de merchandising também apresentou boa consistência interna $(\alpha=0,88)$. Os resultados da tabela 4 demonstram que 
as restrições permitem explicar apenas 7,3\% da intenção de compra de merchandising. Apenas o fator custos mostrou influência negativa nas intenções de compra de merchandising $(B=-0,258)$.

Tabela 4. Análise da regressão dos fatores para explicar as intenções de compra de merchandising

\begin{tabular}{lccccc}
\hline & $\begin{array}{c}\text { Unstandardized } \\
\text { Coefficients }\end{array}$ & $\begin{array}{c}\text { Standardized } \\
\text { Coefficients }\end{array}$ & \\
\hline Fatores & B & $\begin{array}{c}\text { Std. } \\
\text { Error }\end{array}$ & Beta $(B)$ & $t$ & Sig. \\
(Constante) & 3,846 & 0,127 & & 30,171 & 0,000 \\
Acessibilidades & $-0,165$ & 0,128 & $-0,098$ & $-1,292$ & 0,198 \\
Alternativas de Lazer & $-0,169$ & 0,128 & $-0,100$ & $-1,322$ & 0,188 \\
Falta de Interesse e Companhia & $-0,050$ & 0,128 & $-0,030$ & $-0,390$ & 0,697 \\
Falta de Sucesso & $-0,126$ & 0,128 & $-0,075$ & $-0,988$ & 0,325 \\
Custos & $-0,435$ & 0,128 & $-0,258$ & $-3,406$ & 0,001 \\
Falta de Conhecimento & 0,229 & 0,128 & 0,136 & 1,792 & 0,075 \\
Segurança & $-0,022$ & 0,128 & $-0,013$ & $-0,172$ & 0,863 \\
Alternativas de Prática Desportiva & 0,051 & 0,128 & 0,030 & 0,399 & 0,690 \\
Compromissos & $-0,203$ & 0,128 & $-0,121$ & $-1,590$ & 0,114 \\
Localização & 0,091 & 0,128 & 0,054 & 0,711 & 0,478 \\
Programação Desportiva & 0,140 & 0,128 & 0,083 & 1,094 & 0,276 \\
\hline
\end{tabular}

$F(2,161)=62,567, p<0,01 ; R 2=0,137 ; R 2$ ajustado $=0,073$

\section{COMPARAÇÃO INTER-ESPECTADORES NAS RESTRIÇÕES E LEALDADE}

Os resultados dos testes ANOVA permitiram identificar diferenças estatisticamente significativas nas restrições e níveis de lealdade apenas mediante a filiação e as habilitações escolares dos espectadores. Na Tabela 5 são apresentados as diferenças significativas existentes entre os grupos analisados. 
Tabela 5. Diferenças significativas de acordo com associativismo e habilitações escolares

\begin{tabular}{|c|c|c|c|c|c|c|}
\hline \multirow{2}{*}{$\begin{array}{l}\text { Associativismo } \\
\text { Fatores }\end{array}$} & \multicolumn{2}{|c|}{ Sócio } & \multicolumn{2}{|c|}{ Não Sócio } & \multirow[t]{2}{*}{$\mathrm{F}$} & \multirow[b]{2}{*}{ Sig } \\
\hline & Média & $\begin{array}{l}\text { Desvio } \\
\text { Padrão }\end{array}$ & Média & $\begin{array}{l}\text { Desvio } \\
\text { Padrão }\end{array}$ & & \\
\hline Custos & 4,484 & 1,605 & 5,450 & 1,359 & 18,469 & 0,000 \\
\hline Lealdade (assistir a jogos) & 5,651 & ।,255 & 4,751 & 1,490 & 32,053 & 0,000 \\
\hline $\begin{array}{l}\text { Lealdade (comprar } \\
\text { merchandising) }\end{array}$ & 3,993 & 1,716 & 3,444 & 1,692 & 7,497 & 0,007 \\
\hline Habilitações & \multicolumn{2}{|c|}{ Básico e Secundário } & \multicolumn{2}{|c|}{ Superior } & $\mathrm{F}$ & \\
\hline Fatores & Média & $\begin{array}{l}\text { Desvio } \\
\text { Padrão }\end{array}$ & Média & $\begin{array}{l}\text { Desvio } \\
\text { Padrão }\end{array}$ & & Sig \\
\hline Falta de Sucesso & 3,291 & ।,525 & 3,701 & 1,623 & 5,987 & 0,015 \\
\hline
\end{tabular}

Relativamente à comparação entre sócios e não sócios, constata-se que o fator custos é a restrição com maior relevância em termos de diferenciação entre os grupos. É observável que os custos associados à ida ao estádio são uma restrição maior para os não sócios. Verificam-se também diferenças estatisticamente significativas entre estes dois grupos na intenção de assistir a mais jogos e comprar merchandising, sendo que os sócios demonstram ter níveis mais elevados de lealdade do que os não sócios.

Verifica-se ainda que as restrições na ida ao Estádio variam significativamente consoante as habilitações escolares dos inquiridos, sendo o fator falta de sucesso significativamente inferior entre os espectadores com menores habilitações.

\section{DISCUSSÃO}

\section{RESTRIÇÕES E LEALDADE DOS ESPECTADORES DE FUTEBOL}

Através deste estudo pretendeu-se identificar as restrições sentidas pelos espectadores de futebol e perceber a sua influência nos níveis de lealdade, nomeadamente na intenção de assistir a mais jogos e comprar merchandising. Adicionalmente pretendeu-se analisar se as restrições e a lealdade dos espectadores variam consoante as suas caraterísticas sociodemográficas. Considerando-se o propósito do estudo, foram identificadas II restrições. A estrutura fatorial identificada apresenta semelhanças com estudos prévios. Por exemplo, os fatores falta de conhecimento, falta de sucesso, compromissos, custos, alternativas de lazer, localização, alternativas de prática desportiva foram também identificados por Kim e Trail (20 I0). No entanto, os fatores segurança, programação desportiva e acessibilidades são específicos deste estudo, sugerindo que os espectadores benfiquistas valorizam as questões 
relacionadas com a insegurança decorrente de um jogo de futebol profissional bem como as infraestruturas de acesso ao estádio, transportes públicos ou estacionamentos quando decidem assistir a um jogo no estádio. A identificação destes fatores é consistente com estudos prévios que salientam a qualidade dos estádios e o sentimento de segurança durante os jogos como aspectos cruciais para aumentar os níveis de assistência (BISCAIA et al., 2012; THEODORAKIS; ALEXANDRIS, 2008). A inclusão do fator programação desportiva na estrutura fatorial também sugere que a marcação do dia e hora dos jogos tem importância para o espectador na altura de decidir se assiste ou não aos jogos no estádio.

Em relação ao efeito das restrições na lealdade, saliente-se que o fator alternativas de lazer teve o maior impacto explicativo nas intenções de assistir a mais jogos. Este resultado está de acordo com Baade e Tiehen (1990) e Hansen e Gauthier (1989), que apontam para a importância das alternativas de prática desportiva e das alternativas de lazer como restrições importantes nos espectadores de eventos desportivos.

De seguida, os fatores acessibilidades e alternativas de prática desportiva obtiveram o segundo e terceiro maior poder explicativo das intenções de assistir a jogos ao vivo. $\bigcirc$ resultado relativo às acessibilidades é contraditório com Zhang et al. (1996), que verificaram existirem poucos efeitos nas assistências nos estádios decorrentes da satisfação com as acessibilidades e o estacionamento. Assim, e de forma a minimizar as restrições detectadas, seria benéfico para o clube a criação de novos espaços de estacionamento e uma política promotora da utilização do transporte público.

Segundo a literatura, o fator custos é a restrição que maior influência costuma ter nos comportamentos de aquisição de merchandising dos espectadores desportivos (CASPER; KANTERS; JAMES, 2009; BAADE; TIEHEN, 1990, HANSEN; GAUTHIER, 1989; PAN et al., 1997) e foi o que se verificou também neste estudo. Esta restrição foi a que obteve maior poder explicativo das intenções dos espectadores de adquirir merchandising. Este fato pode ser justificado pelos elevados valores cobrados pelo merchandising do clube nas lojas desportivas e oficiais do SLB. Assim, de forma a limitar a restrição provocada pelos custos na aquisição dos produtos do clube, sugere-se a criação de uma política de preços diferenciada por segmentos alvo específicos, tais como sócios e não sócios.

Relativamente à comparação entre grupos, verificou-se também que quanto maior é a habilitação acadêmica do inquirido, maior é a restrição sentida decorrente da falta de sucesso da equipe. Isto indica-nos que um maior grau acadêmico implica uma maior exigência com a prestação desportiva da equipe. Esta restrição tem implicações negativas no que diz respeito à assistência ao jogo (BAADE; TIEHEN, 1990; HANSEN; GAUTHIER, 1989; PAN, et al., 1997). 
Os não sócios são mais influenciados negativamente pelos custos do que os sócios. Tal situação deve levar o SLB a considerar a hipótese de rever o preço dos bilhetes para os não sócios, considerando o interesse de ter o Estádio cheio em todos os jogos. No que se refere à lealdade, verifica-se que os sócios têm comportamentos de lealdade superiores aos não sócios, algo que pode ser explicado naturalmente pela condição de se ser sócio. Um espectador sócio apresenta um maior grau de identificação e internalização com o clube (BISCAIA, et al., 20 I 0).

Verificou-se também uma reduzida participação de mulheres no estudo (19\%). Esta verificação é importante para um gestor desportivo, pois indica que poderá haver possibilidades de atração de sócios femininos. É necessária então a criação de medidas e políticas atrativas para o gênero feminino, de forma a aumentar a participação e assistência aos jogos por parte das mulheres, com o consequente incremento financeiro para o clube. Assim, sugerem-se atividades no estádio direcionadas para o público feminino, ou desenvolvimento e venda de merchandising para este público-alvo (camisetas cor de rosa, cachecóis, etc.).

\section{CONCLUSÕES}

Com a realização deste estudo pretendeu-se caraterizar o adepto de futebol, sublinhando os fatores que mais o restringem na sua decisão de manter comportamentos de lealdade para com o seu clube. Este estudo permite ainda contribuir com informação útil para os gestores desportivos, no quadro das suas metodologias e decisões estratégicas que visem diminuir as restrições sentidas pelos espectadores.

Identificaram-se I | fatores que restringem os espectadores de futebol: (i) acessibilidades; (ii) alternativas de lazer; (iii) falta de interesse e companhia; (iv) falta de sucesso; (v) custos; (vi) falta de conhecimento; (vii) segurança; (viii) alternativas de prática desportiva; (ix) compromissos; (x) localização; e (xi) programação desportiva. Quanto à análise dos fatores explicativos dos comportamentos de lealdade, apurou-se que 3 fatores (acessibilidades, alternativas de lazer e alternativas de prática desportiva) influenciam negativamente as intenções de assistir a jogos e apenas os custos influenciam negativamente as intenções de compra de merchandising. Verificou-se ainda a existência de algumas diferenças significativas entre sócios e não sócios. $\bigcirc$ fator custos foi mais sentido como restrição à assistência a um jogo de futebol no estádio por parte dos não sócios, do que pelos sócios. Também relativamente aos comportamentos de lealdade (intenções de assistir a jogos e intenções de compra de merchandising), verificou-se uma vez mais que os não sócios tiveram valores inferiores de lealdade do que os associados. Por fim, analisando-se as diferenças inter grupos de acordo com as habilitações escolares, observou-se que o único fator com relevância estatística na diferenciação dos espectadores foi o fator falta de sucesso. Esta restrição interna é sentida de uma forma mais acentuada pelos inquiridos com habilitações superiores. 
Foi notória a reduzida participação de inquiridos neste estudo $(n=305)$, tendo em conta o universo de sócios e adeptos benfiquistas. Assim, em estudos posteriores deverão obter-se amostras maiores de forma a confirmar-se os dados obtidos.

Será também interessante efetuarem-se estudos em diferentes alturas da época desportiva, pois é possível que a percepção das restrições se altere em função da fase da época e do sucesso desportivo (vitória/derrota). Compreender a relevância dos bilhetes de época nas restrições e lealdade sentidas pelos espectadores é algo a ter também em conta em estudos futuros. A realização de estudos similares em diferentes clubes desportivos e para modalidades diferentes também é recomendável, de forma a melhor se compreenderem as dinâmicas que influenciam as restrições dos espectadores desportivos em geral, e dessa forma fornecer uma ferramenta útil aos gestores desportivos.

\section{Influence of Constraints on Soccer Attendance Loyalty: Sport Lisboa e Benfica}

ABSTRACT: The purpose of this study was to analyse the influence of constraints on the soccer spectators' loyalty. An online survey was applied to Sport Lisboa e Benfica fans and through an exploratory factor analysis, I I factors were identified. The results of a linear regression showed that 4 have significant influence in spectators' loyalty. The ANOVA results showed significant differences in the constraints felt by members and non-members, as well as among spectators with different academic degrees. As for loyalty, there are differences among members and non-members. Managerial implications of these results are discussed and suggestions for future research are provided.

KEYWORDS: Constraints; Loyalty; Soccer; Attendance.

\section{Influencia de los constreñimientos en la lealtad de los espectadores del fútbol: Sport Lisboa e Benfica}

RESUMEN: El objetivo del estudio fue analizar la influencia de los constreñimientos en la lealtad de los espectadores del fútbol. Se ha aplicado un cuestionario a adeptos del Sport Lisboa e Benfica y a través de un análisis factorial exploratoria se identificaron I I factores. Un análisis de regresión linear permitió identificar que 4 influencian significativamente la lealtad de los adeptos. Los resultados de ANOVA identificaron la existencia de diferencias estadísticamente significativas entre los constreñimientos sentidos por socios y non socios, bien como entre espectadores con diferentes habilitaciones escolares. Cuanto à la lealtad, se verificaron diferencias entre socios y non socios. Las implicaciones de los resultados son discutidas y se proveen sugestiones para futuras pesquisas.

PALABRAS-CLAVE: Constreñimientos; lealtad; fútbol; espectadores. 


\section{REFERÊNCIAS}

ALEXANDRIS, K.; CARROLL, B. An analysis of leisure constraints based on different recreational sport participation levels: Results from a study in Greece. Leisure Sciences, London, v. 19, n. I, p. I-15, jan. 1997.

BAADE, R.; TIEHEN, L. An analysis of major league baseball attendance, 1969 - 1987. Journal of Sport and Social Issues, Boston, v. 14, n. I, p. 14-32, mar. 1990.

BEE, C.; HAVITZ, M. Exploring the relationship between involvement, fan attraction, psychological commitment and behavioural loyalty in a sports spectator context. International Journal of Sports Marketing \& Sponsorship, Bristol, v. I I. n. 2, p. I40- I57, jan. 2010.

BISCAIA, R. et al. Valor da marca e lealdade ao clube: A influência do valor da marca na lealdade ao clube em sócios e não sócios. In: CONGRESSO NACIONAL DE GESTÃO DO DESPORTO, II., 2010, Lagos. Anais... Lagos, out. 2010.

BISCAIA, R. et al. Members' segmentation, service quality and behavioral intentions: A case study of a professional football team. Revista Intercontinental de Gestão Desportiva, Porto, v. 2, p. 33-44, dez. 2012.

CASPER, J.; KANTERS, M.; JAMES, J. Perceptions of constraints to NHL spectatorship. International Journal of Sport Management and Marketing, London, v. 5, n. I/2, p. 55-72, 2009.

DALE, B. et al. Service improvement in a sports environment: a study of spectator attendance, managing service quality, ABI/INFORM Global, Cambridge, v. I 5, n. 5, p. 470-484, may 2005.

DELOITTE. Annual review of football finance. Highlights. jun. 2010. Disponível em: <http://www.deloitte.com/assets/Dcom-UnitedKingdom/Local\%20Assets/Documents/ Industries/Sports\%20Business\%20Group/UK_SBG_ARFF2010_Highlights.pdf. > Acesso em: 15 june 2011 .

HANSEN, H.; GAUTHIER, R. Fators affecting attendance at professional sport events. Journal of Sport Management, Illinois, v. 3, n. I, p. 15-32, jan. 1989.

INGEN, E.; EIJCK, K. Leisure and social capital: as analysis of types of company and activities. Leisure Sciences, London, v. 31 , n. 2, p. 192-206, mar. 2009.

JACKSON, E.; CRAWFORD, D.; GODBEY, G. Negotiation of leisure constraints. Leisure Sciences, London, v. 15, n. I, p. I-II, jan. 1993.

JACKSON, E. Will research on leisure constraints still be relevant in the twenty-first century? Journal of Leisure Research, Illinois, v. 32, n. I, p. 62-68, mar. 2000.

KIM, Y.; TRAIL, G. Constraints and motivators: a new model to explain sport consumer behaviour. Journal of Sport Management, Illinois, v. 24, n. 2, p. 190-210, mar. 2010.

LIGA PORTUGUESA DE FUTEBOL PROFISSIONAL. Painel de Espetadores. Site Oficial. 20 I I. Disponível em: <http://www.lpfp.pt/futebol/pages/espectadores.aspx?epoca=20 I0 20 I I\&competicao=liga_zon_sagres $>$ Acesso em: 20 Jul. 201 I . 
MAHONEY, D.; MADRIGAL, R; HOWARD D. Using the psychological commitment to team (PCT) scale to segment sport consumers based on loyalty. Sport Marketing Quarterly, West Virginia, v. 9, n. I, p. 15-25, mar. 2000.

MARIVOET, S. Hábitos desportivos da população portuguesa. Lisboa: Instituto Nacional de Formação e Estudos de Desporto. 200। . 194p.

MAROCO, J. Análise estatística com o PASW statistics (ex-SPSS). Pêro Pinheiro: Report Number, 2010.

NEALE, L.; FUNK, D. Investigating motivation, attitudinal loyalty and attendance behavior with fans of Australian football. International Journal of Sports Marketing \& Sponsorship, Bristol, v. 7, n. 4, p. 307-317, july 2006.

PAN, D. W. et al. Factors and differential effects on purchases of season tickets for intercollegiate basketball games. Journal of Sport Behavior, South Alabama, v. 20, n. 4, p. I25-142, dec. 1997.

PETRICK, J. et al. Analysis of golfer motivations and constraints by experience use history. Journal of Leisure Research, Illinois, v. 33, n. I, p. 56-70, mar. 2001.

RICHELIEU, A.; LOPEZ, S.; DESBORDES, M. The internationalization of a sports team brand: the case of european soccer teams. International Journal of Sports Marketing \& Sponsorship, Bristol, v. 10, n. I, p. 29-44, oct. 2008.

TAPP, A. The loyalty of football fans: we'll support you evermore?. Database Marketing \& Customer Strategy Management, Hants, v. II , n. 3, p. 203-2I 5, apr. 2004.

THEODORAKIS, N.; ALEXANDRIS, K. Can service quality predict spectators' behavioral intentions in Professional soccer? Managing Leisure, London, v. I3, n. 3-4, p. I 62- I 78, july 2008.

YOSHIDA, M.; JAMES, J. Customer satisfaction with game and service experiences: antecedents and consequences. Journal of Sport Management, Illinois, v. 24, n. 3, p. 338-36I, may 2010.

ZHANG, J. et al. Spectator knowledge of hockey as a significant predictor of game attendance. Sport Marketing Quarterly, West Virginia, v. 5, n. 3, p. 4I-48, sept. 1996.

Recebido em: 10 set. 2012

Aprovado em: 4 fev. 2013

Endereço para correspondência: Jorge Miguel Rodrigues de Pina Cardoso Prct. Armada das Índias, $n^{\circ} 63^{\circ} \mathrm{B}$

2735-06 I Agualva Portugal 